\title{
Vasoactive intestinal peptide receptor-based imaging and treatment of tumors (Review)
}

\author{
BO TANG ${ }^{1}$, XIN YONG $^{1}$, RUI XIE ${ }^{1},{\text { QIAN-WEI } \mathrm{LI}^{2} \text { and SHI-MING YANG }}^{1}$ \\ ${ }^{1}$ Department of Gastroenterology, Xinqiao Hospital, Third Military Medical University, Chongqing 400037; \\ ${ }^{2}$ Department of Nuclear Medicine, Southwest Hospital, Third Military Medical University, Chongqing 400038, P.R. China
}

Received October 15, 2013; Accepted November 22, 2013

DOI: 10.3892/ijo.2014.2276

\begin{abstract}
Vasoactive intestinal peptide receptors (VIPRs) are members of the G-protein-coupled receptor superfamily. These receptors are overexpressed in many common malignant tumors and play a major role in the progression and angiogenesis of a number of malignancies. Therefore, VIPRs may be a valuable target for the molecular imaging of tumors and therapeutic interventions. The specific natural ligand or its analogs can be labeled with a radionuclide and used for tumor receptor imaging, which could be used to visualize VIPR-related surface protein expression in vivo and to monitor the in vivo effects of molecular drugs on tumors. Moreover, the involvement of VIPRs in malignant transformation and angiogenesis renders them potential therapeutic targets for cancer treatment. A variety of VIP antagonists and cytotoxic VIP conjugates have been synthesized and evaluated for VIPR-targeted molecular therapy. The importance of VIPRs in tumor biology and the ability to predict responses to targeted therapy and monitor drug interventions suggest that VIP receptor-based imaging and treatment will be critical for the early diagnosis and management of cancer. Here, we review the current literature regarding VIPRs and their natural ligands and the involvement of VIPRs in tumor growth and angiogenesis, with an emphasis on the present use of VIPRs for the molecular imaging of tumors and therapies targeting VIPRs.
\end{abstract}

Correspondence to: Professor Shi-Ming Yang, Department of Gastroenterology, Xinqiao Hospital, Third Military Medical University, 183 Xinqiao Street, Chongqing 400037, P.R. China E-mail: shimingyang@yahoo.com

Abbreviations: VIP, vasoactive intestinal peptide; PACAP, pituitary adenylate cyclase-activating polypeptide; PHM, peptide histidine methionine amide; GRF, growth-hormone-releasingfactor; PHI, peptide histidine isoleucine; GPCR, G-protein-coupled receptor; SPECT, single photon emission computed tomography; PET, positron emission tomography; CT, computed tomography; MRI, magnetic resonance imaging; FDG, fluorodeoxyglucose; PRRT, peptide-receptor radionuclide therapy

Key words: VIP, VIP receptor, peptides, imaging, therapy, cancer

\section{Contents}

1. Introduction

2. Structural and functional features of VIP/PACAP and VIPRs

3. VIP receptors as potential targets for imaging and therapy

4. Targeting VIPRs for molecular imaging

5. ${ }^{123}$ I-labeled VIP for receptor imaging

6. ${ }^{99 \mathrm{~m}} \mathrm{Tc}$-labeled VIP analogs for receptor imaging

7. PET molecular imaging of the VIP receptor

8. Targeting VIP receptor for cancer molecular therapy

9. Prospective and Conclusion

\section{Introduction}

Malignant tumors have become one of the most lethal diseases in humans, and the incidence, diagnostic studies and therapeutic options for tumor treatment have undergone major changes in recent years. Currently, the standard treatment for a malignancy includes surgical resection followed by the delivery of chemotherapeutic agents. Although surgical resection is the preferred choice for early-stage solid tumors, it is not a suitable treatment for invasive, metastatic or hematologic malignancies. The overall toxicity and the side effects of chemotherapy also limit the dose regimen, thus requiring a relatively narrow therapeutic index, which can lead to insufficient and/or unpredictable responses. Furthermore, during the course of therapy, multidrug resistance can severely limit the effectiveness of chemotherapy and is also associated with tumor recurrence (1-4). Therefore, it is desirable to target therapeutic molecules to primary tumors and their metastases, which represents a major challenge for improving current cancer therapy (5). Another significant challenge is the development of strategies that can guide the use of these targeted molecules and enable the specific delivery of therapeutic agents to malignant tissues (6). Targeted therapies generally take advantage of biological molecules that are uniquely expressed or significantly overexpressed in tumors. Hormone receptors were some of the earliest targets utilized for the targeted treatment of many cancers, such as breast, prostate and thyroid cancers $(7,8)$. Therefore, the molecular imaging of the expression of tumor-related receptors is advantageous because it provides information for receptor-targeted therapy (9). 
Molecular imaging has been defined as the visualization, characterization and measurement of biological processes at the molecular and cellular levels (10). Tumor receptor imaging is an important type of molecular imaging and can be used to assess receptor expression for the entire disease burden to facilitate early diagnosis, suggest personalized therapy options, and monitor the in vivo effects of a drug on its target. Different receptors are overexpressed in specific tumor types. Several tumor receptors have been utilized for imaging and therapy, including somatostatin receptors, human epidermal growth factor receptor 2 (HER2), integrin receptors, epidermal growth factor receptor (EGFR), and vasoactive intestinal peptide receptors (VIPRs). Vasoactive intestinal peptide receptors (VIPRs) are highly overexpressed in human tumors and metastases. VIPRs also play a major role in the progression of a number of malignancies, thus suggesting that these receptors may serve as molecular targets for cancer diagnosis and treatment. Herein, we describe the biology of VIPRs and VIPR-targeting agents and discuss the potential application of VIPRs for the diagnosis and treatment of cancer.

\section{Structural and functional features of VIP/PACAP and VIPRs}

Vasoactive intestinal peptide (VIP) and pituitary adenylate cyclase-activating polypeptide (PACAP) are two members of a structurally related family of peptides that includes mammalian peptide histidine methionine amide (PHM), secretin, glucagon, and growth hormone-releasing factor (GRF) (11). VIP was isolated from the small intestine of a pig and was characterized in the early 1970s by Mutt and Said. VIP exhibits various physiological effects, including increased vasodilatation and reduced arterial blood pressure (12), smooth muscle relaxation (13), stimulation of electrolyte secretion (14), immunosuppression, hormonal secretion, cell proliferation and increased gastric motility $(15,16)$. The human VIP gene is located on chromosome 6 at band q25 $(17,18)$ and encodes the 170 -amino acid precursor protein, prepro-VIP, which undergoes post-translational modification to produce the 28 amino acid VIP peptide $(12,19)$, in addition to the 27 aa peptide histidine methionine (PHM) in humans or the peptide histidine isoleucine (PHI) in rodents (20). These two peptides are co-synthesized with VIP as part of the same precursor peptide, which is encoded by an adjacent exon in the human genome, suggesting that the family of peptides has evolved via exon duplication coupled with gene duplication (21). The N-terminus of VIP plays an important role in this protein's biological activity, and several studies have shown that the N-terminus is essential for receptor activation; however, it is not involved in the recognition of the receptor-binding site, which seems to involve amino acids in the C-terminal domain $(22,23)$. The human PACAP gene is located on chromosome 18p11 and encodes a 176-amino acid precursor protein (preproPACAP) that contains PACAP and PACAP-related peptide (PRP) in the $\mathrm{C}$-terminal domain and a 24 amino acid signal protein in the N-terminal domain $(23,24)$.

These two peptides share a similar sequence and exert their functions through the binding of vasoactive intestinal peptide receptors (VIPRs), which are functional receptors for VIP and PACAP. VIPRs are members of the G-protein-coupled receptor (GPCR) family, which is comprised of three classes of receptors: VPAC1, VPAC2 and PAC1. VPAC1 and VPAC2 respond to VIP and PACAP with comparable affinity, whereas PAC1 displays a high affinity for PACAP and a low affinity for VIP (25-27). The VIPRs share a similar structural organization; they contain seven transmembrane domains (TM), a large N-terminal segment that includes the binding site of VIP/ PACAP, and an intracellular C-terminal region that is associated with signal transduction (28). Upon ligand binding, these receptors mediate their signal transduction activity via the binding of heterotrimeric G-proteins to the receptor's intracellular loop, which ultimately results in cAMP production $(29,30)$, protein kinase A (PKA) pathway activation $(25,26)$, inositol phosphate (IP) turnover (23), the activation of MAPKs (mitogen-activated protein kinases) $(31,32)$, and the activation of the $N F-\kappa B$ pathway (Fig. 1) (33).

The effects of VIP and PACAP are mediated by VIPRs and have many overlapping functions. These peptides play roles in the gastrointestinal, immune, reproductive, respiratory, cardiovascular and endocrine systems $(34,35)$. For example, VIP is involved in gut motility and acts as a potent vasoregulatory hormone, whereas PACAP is associated with the nervous system and exerts a hypophysiotropic effect on pituitary hormone secretion $(11,23)$. In addition to the crucial roles that VIPRs play in many physiological processes, VIPRs are involved in the progression of a number of malignancies and can stimulate tumor growth and angiogenesis through the transactivation of epidermal growth factor receptor (EGFR) and the expression of vascular endothelial growth factor (VEGF) $(36,37)$.

\section{VIP receptors as potential targets for imaging and therapy}

VIPRs have been identified in several normal tissues and in various types of tumors. In normal human tissues, VPAC1 receptors are abundant in the brain, $\mathrm{T}$ lymphocytes, and most peripheral tissues including the liver, lungs and intestines $(38,39)$. VPAC2 receptors are mainly expressed in the hippocampus, the brainstem, the spinal cord, and most smooth muscle tissues $(39,40)$. PAC1 receptors are predominantly found in the adrenal medulla and on the surface of neuroendocrine neoplasms $(41,42)$. However, VIPRs are highly overexpressed in the majority of human tumors and are particularly common in frequently occurring cancers. Reubi et al (43) reported that VPAC1 receptors are overexpressed in most frequently occurring malignant epithelial neoplasms, such as cancers of the colon, breast, lungs and prostate, in a pattern similar to that found in normal tissues. In contrast to the ubiquitous expression of VPAC1 receptors in most human tumors, tumors that express VPAC2 receptors are rare, and this phenomenon is only observed in some leiomyomas and gastrointestinal stromal tumors $(43,44)$. A high incidence of PAC1 receptor expression was found in neuroendocrine neoplasms located in the brain and the endocrine and neuroendocrine systems and included gliomas, neuroblastomas, and pituitary adenomas, as well as endometrial cancers (43). The VIPRs are significantly overexpressed in most human tumors, and the differences in the cell surface receptor profiles between cancer cells and their normal counterparts can be utilized as a molecular signature for targeted imaging. Thus, the VIPRs may be potential targets for molecular imaging. 


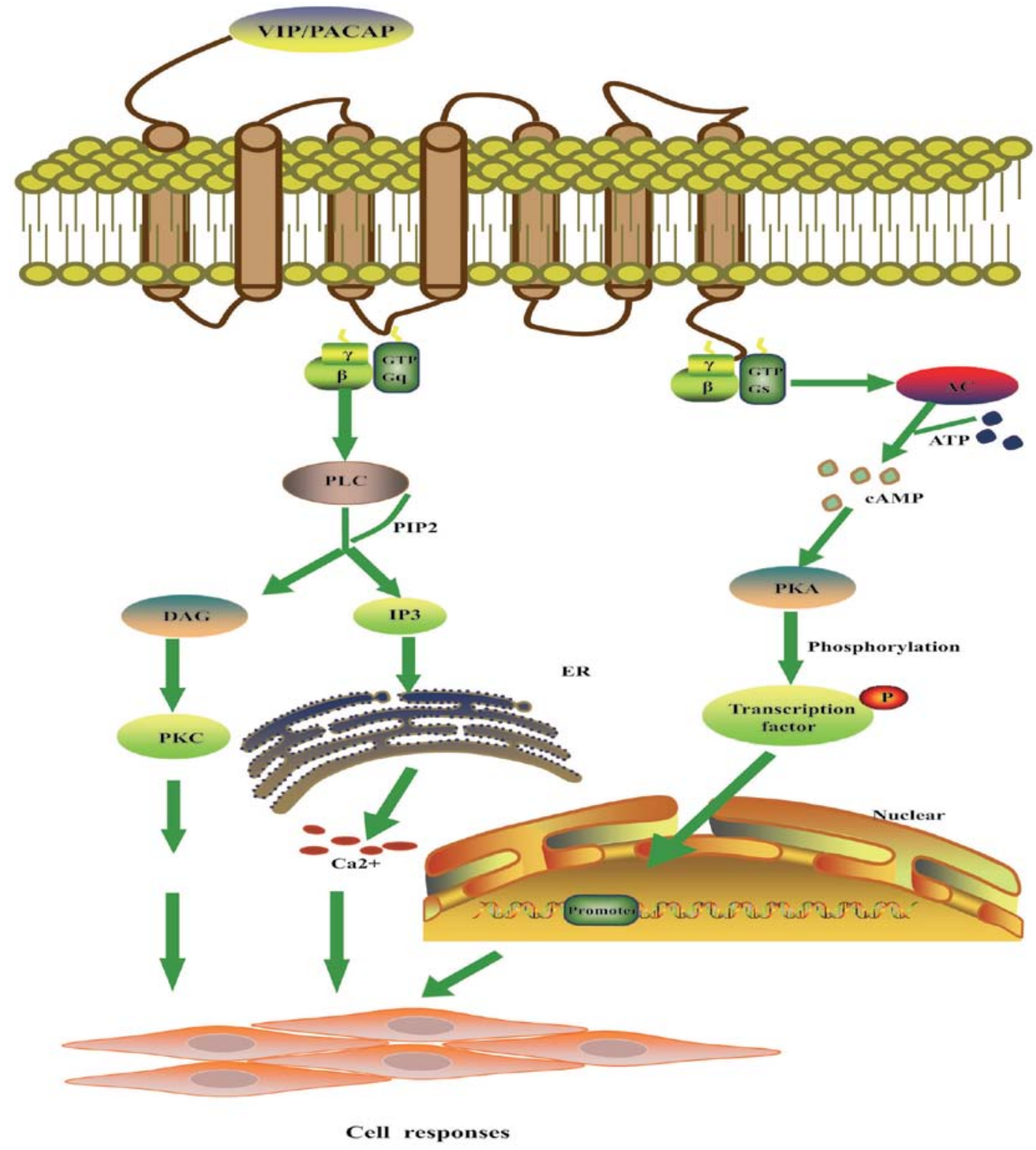

Figure 1. Molecular mechanism of VIP signal transduction. The main signals of VIP are mediated through VIP/PACAP receptors via coupling to adenylate cyclase (AC)-stimulation G protein and PI signal transduction pathways. AC-cAMP pathway: VIP and receptor binding triggers the GDP-GTP exchange of the Gs protein and activate AC. AC catalyzes the synthesis of cAMP from ATP, and cAMP elicits its cellular responses by the phosphorylation of a number of cellular proteins or transcription factors via cAMP-dependent protein kinase (PKA). PI pathway: VIP and receptor binding is coupled to Gq protein and activates phospholipase C (PLC), which cleaves PIP2 into DAG and IP3. DAG activates PKC which in turn phosphorylates a number of cellular proteins and exerts biological functions. $\mathrm{IP}_{3}$ causes the release of $\mathrm{Ca}^{2+}$ from endoplasmic reticulum (ER) which leads to exocytosis and various other cellular responses. cAMP, cyclic adenosine 5'-monophosphate; GTP, guanosine 5'-triphosphate; DAG, diacylglycerol; IP3, inositol-1,4,5-triphosphate; PIP2, phosphatidylinositol-4,5-bisphosphate.

It is well documented that excessive VIPR signaling, which arises from receptor overexpression and autocrine stimulation by VIP/PACAP or other factors, is a hallmark of a wide variety of tumors. Previous research has shown that the serum levels of VIP in several tumors are significantly increased, which may serve as an indicator of the presence of certain tumors and could become a part of their diagnosis (45). Since most tumors overexpress VIPRs, VIP/PACAP can bind to these VIPRs and activate them, leading to an interaction with a stimulatory guanine nucleotide binding protein (Gs) and ultimately resulting in the stimulation of adenylate cyclase. Research has shown that the addition of VIP to lung cancer cells elevated the cAMP levels and led to the activation of a series of transcription factors that promoted the expression of nuclear oncogenes and growth factors (46,47). In addition, VIP activation increased the secretion of VEGF and facilitated tumor angiogenesis via the cAMP/PKA and PI3K signaling pathways (36). The involvement of VIPRs in malignant transformation and angiogenesis renders them potentially valuable targets for cancer therapy.

\section{Targeting VIPRs for molecular imaging}

Tumor receptor imaging plays an important role in molecular imaging, the characterization of receptor expression, tumor biology, the identification of molecular targets, and the application of targeted cancer therapy (48). The advantages of tumor receptor imaging include its noninvasive nature, 
the ability to assess receptor expression, and the ability to evaluate the in vivo effects of the drug on the tumor. Several types of imaging agents may be used for the imaging of receptors that are overexpressed in tumors, including antibodies or their fragments, natural peptide ligands or their analogs, and non-peptide small molecules. Although the introduction of antibodies as specific agents to target malignant tumors dates back almost 35 years, these proteins are insufficient for tumor receptor imaging due to their high molecular weight, slow targeting of the tumor, slow clearance from the blood and normal tissues, and relatively low tumor to non-tumor ratios when used in tumor imaging and therapy $(49,50)$. In general, natural ligands and small ligand analogs for targeted imaging are the most common imaging agents in use because small peptide ligands are small and readily diffusible and have rapid kinetics (51). Another important molecular imaging tool is the use of a tracer that accumulates at the sites of targeted receptors. Most molecular imaging tracers include a reporter moiety that emits a signal that can be detected by a special external device and a linker joining the reporter moiety to the targeted ligands. Some of the most commonly used tracers are radionuclide-labeled probes and optical imaging probes. However, the tissue penetration of optical signals is limited to a few millimeters and thus limits the clinical application of optical imaging probes. Therefore, radionuclide-based tracers dominate in clinical molecular imaging techniques due to their high sensitivity and increased tissue penetration. Currently, there are two major radionuclide-based imaging methods used in the pre-clinical or clinical settings: single photon emission computed tomography (SPECT) and positron emission tomography (PET). For the reasons stated above, we focus on radionuclide-labeled peptide ligands and small molecule analogs used for SPECT and PET imaging in this review.

\section{5. ${ }^{123}$ I-labeled VIP for receptor imaging}

Virgolini et al (52) first reported that ${ }^{123}$ I-labeled VIP could be successfully used in vivo to scan patients with gastrointestinal adenocarcinomas, carcinoids and insulinomas. After the intravenous injection of the ${ }^{123}$ I-labeled VIP, $~ 45 \%$ of the radioactivity was found in the lungs within $30 \mathrm{~min}$, and the activity decreased rapidly. Visualization of the primary tumors and metastases was possible within an hour of injection and was still apparent at 24-h post-injection. Most importantly, radiolabeled VIP-receptor scanning is more advantageous than CT scanning because receptor imaging is based on the receptor expression pattern rather than the macroscopic morphology (52). Subsequently, the same group performed a series of clinical studies in which ${ }^{123}$ I-labeled VIP was used to image various tumors, such as colorectal cancers (53), pancreatic cancers (54), VIPomas (55), and endocrine tumors (56). These imaging results exhibited a high sensitivity, which was an advantage over CT scanning, particularly in patients with tumors of a small size. Raderer et al (57) compared the in vitro and in vivo binding of ${ }^{123} \mathrm{I}-\mathrm{VIP}$ and an ${ }^{111} \mathrm{In}-$ labeled monoclonal antibody specific to the TAG-72 protein in patients with intestinal adenocarcinomas in a single-blinded prospectively randomized trial. The results indicate that VIP receptor scanning is more sensitive than immunoscintigraphy for the localization of intestinal adenocarcinomas and metastatic spread (57). Although ${ }^{123}$ I-VIP has promising potential to localize even small tumors expressing VIPRs and is useful for the early diagnosis and treatment of tumors, naturally occurring peptides like VIP exhibit limitations for in vivo tumor imaging because they have a short biological half-life and are rapidly degraded in the liver and kidneys. Due to this metabolic instability, native VIP peptides require further chemical modifications to improve their bioavailability for receptor binding prior to their use in tumor receptor imaging. In addition, the radionuclide ${ }^{123} \mathrm{I}$ is generated by an expensive cyclotron instrument, which increases the cost of treatment. Furthermore, radiolabeled VIP requires further isolation and purification, which greatly limits its clinical applications. Therefore, novel stable analogs of VIP and applicable radionuclides are required for VIPR imaging.

\section{6. ${ }^{99 m}$ Tc-labeled VIP analogs for receptor imaging}

In contrast to ${ }^{123} \mathrm{I},{ }^{99 \mathrm{~m}} \mathrm{Tc}$ has excellent physical characteristics for scintigraphic imaging, is very inexpensive, and is produced by a ${ }^{99} \mathrm{Mo}$ generator system (Table I) (58). In an initial attempt to employ ${ }^{99 \mathrm{~m}} \mathrm{Tc}$ labeling, the $\mathrm{N}$ terminus (His1) of VIP was conjugated to one of two well-known bi-functional chelating agents (BFCAs): CPTA [4-(1,4,8,11-tetraazacyclotetradec-1-yl) methyl] benzoic acid or $\mathrm{MAG}_{3}[\mathrm{~N}-[\mathrm{N}[\mathrm{N}$-(benzylthio) acetyl]glycyl] glycyl] glycine]. These compounds have two major drawbacks: radiochemical impurity and a loss of biological function. It was found that the histidine residue in the number one position of VIP played an important role in the biological activity of VIP (59).

To improve the radiolabeling efficiency, Thakur et al (60) further modified VIP at the carboxy terminus of $\mathrm{Asn}^{28}$. The research group chose to use 4-aminobutyric acid (Aba) as the spacer and extended the molecule to include Gly-Gly-(D)Aba-Gly, which resulted in an $\mathrm{N}_{4}$ configuration that could be used for the chelation of ${ }^{99 \mathrm{~m} T c}$ (Fig. 2). This modified analog was referred to as TP3654 (VIP labeled with ${ }^{99 \mathrm{~m}} \mathrm{Tc}$ ). The biological activity of ${ }^{99 \mathrm{~m}} \mathrm{Tc}-\mathrm{TP} 3654$ was equivalent to that of the native VIP peptide, and the 24-h tumor uptake of ${ }^{99 \mathrm{~m}} \mathrm{Tc}-\mathrm{TP} 3654$ was higher than that of ${ }^{123} \mathrm{I}$-VIP. These results implied that a simple and efficient hybrid peptide technique had been developed for labeling peptides with ${ }^{99 \mathrm{~m}} \mathrm{Tc}$. Subsequently, Thakur et al $(58,60,61)$ evaluated the pharmacokinetics and imaging characteristics of ${ }^{99 \mathrm{~m}} \mathrm{Tc}-\mathrm{TP} 3654$ in normal volunteers and patients with a history of cancer. No adverse reactions or changes were noted in the imaging process. Furthermore, $\sim 70 \%$ of the injected radioactivity was eliminated in the urine, and $20 \%$ was cleared through the liver. The tumor uptake of ${ }^{99 \mathrm{~m}}$ Tc-TP3654 was significantly higher than that of ${ }^{111}$ In-octreotide, which is concordant with the higher VIP receptor density observed in most tumors when compared to the density of somatostatin receptors. This VIP analog promises to be a nontoxic and reliable agent for imaging human tumors that overexpress VIPRs.

Kothari et al (62) synthesized three VIP analogs functionalized at the $\mathrm{N}$ terminus with histidine [VP05 (28 residue), VD4 (20 residue), VD5 (19 residue)] by solid phase synthesis and radiolabeled the VIP analogs with ${ }^{99 \mathrm{~m}} \mathrm{Tc}$ via a novel tricarbonyl synthon. All of the radiolabeled complexes were stable at room temperature and were produced with high yields. 
Table I. Radionuclides for labeling of molecular imaging and therapeutic probes.

\begin{tabular}{lclll}
\hline Nuclide & Half-life $(\mathrm{h})$ & Production & Energy (keV) & Application \\
\hline${ }^{99 \mathrm{~m} \mathrm{Tc}}$ & 6.01 & Generator & $\gamma 140$ & SPECT imaging \\
${ }^{123} \mathrm{I}$ & 13.27 & Cyclotron & $\gamma 159$ & SPECT imaging \\
${ }^{18} \mathrm{~F}$ & 1.8 & Cyclotron & $\beta^{+} 634 \gamma 511$ & PET imaging \\
${ }^{64} \mathrm{Cu}$ & 12.7 & Cyclotron & $\beta^{+} 655 \beta^{-} 573$ & PET imaging \\
${ }^{111} \mathrm{In}$ & 67 & Cyclotron & $\gamma 171$ Auger e- 30 & SPECT imaging \\
${ }^{68} \mathrm{Ga}$ & 1.1 & Generator & $\beta^{+} 1899 \gamma 511$ & PET imaging \\
${ }^{90} \mathrm{Y}$ & 65 & Generator & $\beta^{-} 2964$ & Therapy \\
${ }^{131} \mathrm{I}$ & 192 & Cyclotron & $\beta^{+} 607 \gamma 364$ & Therapy \\
${ }^{177} \mathrm{Lu}$ & 161 & Cyclotron & $\beta^{-} 498 \gamma 208$ & Therapy \\
\hline
\end{tabular}

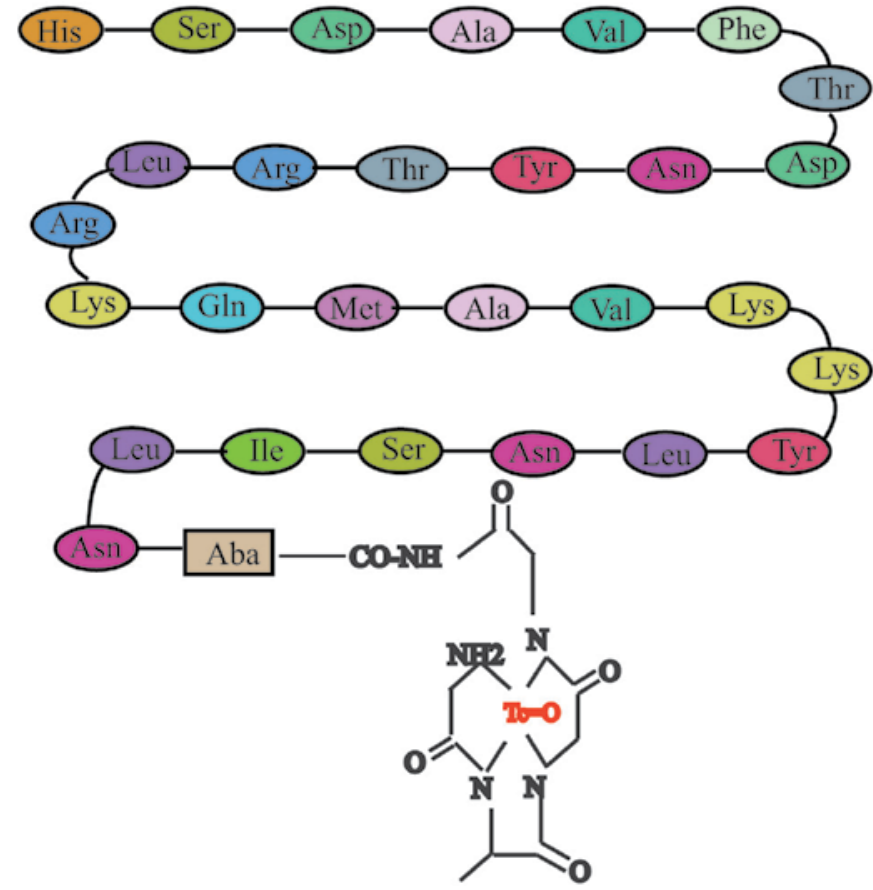

Figure 2. Amino acid sequence and proposed structure of ${ }^{99 \mathrm{~m}} \mathrm{Tc}-\mathrm{TP} 3654$. Gly-Gly-(D)-Aba-Gly is used as a chelating moiety that provides an $\mathrm{N}_{4}$ configuration for chelation with ${ }^{99 \mathrm{~m}} \mathrm{Tc}$ which has been shown to bind ${ }^{99 \mathrm{~m}} \mathrm{Tc}$ strongly and efficiently. In addition, the 4-aminobutyric acid (Aba) is used as the spacer to extend the molecule including Gly-Gly-(D)-Aba-Gly. VIP-AbaGly-Gly-(D)-Ala-Gly had the observed molecular weight of 3654.48 and is referred to as TP3654.

Biodistribution studies revealed good tumor uptake kinetics; however, the soft tissue uptake was also high due to the lipophilic nature of the peptide. Thus, more research is required to modify the reported analogs and create novel radiolabeled analogs to enhance their ability to target VIP receptors.

\section{PET molecular imaging of the VIP receptor}

Although PET is not as widely available as SPECT, PET is advantageous for tumor diagnosis because it exhibits higher resolution and sensitivity than computed tomography (CT), magnetic resonance imaging (MRI) and SPECT. Therefore, labeling VIP with positron emission radionuclides is important for PET molecular imaging of tumors expressing VIP receptors. Moody et al (63) used ${ }^{18} \mathrm{~F}$ to radiolabel VIP analogs (at $\mathrm{Arg}^{15} /$ $\left.\mathrm{Arg}^{21}\right)$ and obtained a labeled complex ( $\left.{ }^{18} \mathrm{~F}-\mathrm{RR}\right)$ VIP that bound to breast cancer cells with high specificity and affinity and acted as an agonist. The tumor imaging results showed that $4 \mathrm{~h}$ after injection, the density of $\left({ }^{18} \mathrm{~F}-\mathrm{RR}\right) \mathrm{VIP}$ was 4 -fold greater in the tumor than in the normal tissue with the highest uptake (intestinal) and was $\sim 15$-fold greater than in the normal breast, indicating that $\left({ }^{18} \mathrm{~F}-\mathrm{RR}\right)$ VIP could localize to breast tumors in vivo. However, a comparison of $\left({ }^{18} \mathrm{~F}-\mathrm{RR}\right) \mathrm{VIP}$ and ${ }^{18} \mathrm{~F}-\mathrm{FDG}$ showed that FDG exhibited a 2- to 3-fold greater tumor accumulation and target-to-non-target ratio relative to $\left({ }^{18} \mathrm{~F}-\mathrm{RR}\right)$ VIP (64). To further improve the stability and biodistribution characteristics of ${ }^{18} \mathrm{~F}$-labeled VIP, Cheng et al $(65,66)$ synthesized $\left(\mathrm{R}^{8,15,21}, \mathrm{~L}^{17}\right)$ VIP by replacing Asp8, Lys15, and Lys21 with Arg and Met17 with Leu in the amino acid sequence of VIP. The radiolabeled ${ }^{18} \mathrm{~F}-\left(\mathrm{R}^{8,15,21}, \mathrm{~L}^{17}\right)$ VIP was obtained with high radiochemical purity, high specific radioactivity and good stability in vitro. Biodistribution data showed higher tumor-to-muscle and tumor-to-blood ratios, indicating its potential application as a PET imaging agent for tumors overexpressing VIPRs.

The radionuclide ${ }^{64} \mathrm{Cu}$ has a longer half-life and a wealth of known chemistry and provides nearly quantitative yields so that the radiolabeled compound can be prepared without further purification (Table I). ${ }^{64} \mathrm{Cu}-1,4,8,11$-tetraazacyclotetradecane -1,4,8,11-tetraacetic acid (TETA) VIP was the first reported ${ }^{64} \mathrm{Cu}$-VIP analog, but no further preclinical or clinical data have been reported (67). Subsequently, Thakur et al (68) synthesized the VIP analog TP3982 to harbor a carboxy-terminal lysine residue separated from asparagine by 4-aminobutyric acid (Aba) as a spacer. The biological activity of ${ }^{64} \mathrm{Cu}-\mathrm{TP} 3982$ was not compromised. It also exhibited in vivo stability and a 74-fold increase in tumor uptake relative to ${ }^{99 \mathrm{~m}} \mathrm{Tc}-\mathrm{TP} 3654$, which had previously been successfully used to image human tumors. Thus, ${ }^{64} \mathrm{Cu}$-TP3982 is a desirable PET imaging agent for the imaging of cancers overexpressing VIPRs. Zhang et al $(69,70)$ used the same method to synthesize the VIP analog TP3939 and label it with ${ }^{64} \mathrm{Cu}$. The imaging data obtained for ${ }^{64} \mathrm{Cu}-\mathrm{TP} 3939$ in experimental and spontaneous prostate cancer indicated that with its uncompromised biological activity, ${ }^{64} \mathrm{Cu}-\mathrm{TP} 3939$ could detect xenografts and cases of occult prostate cancer that were not detectable with ${ }^{18} \mathrm{~F}-\mathrm{FDG}$ or CT. Thus, ${ }^{64} \mathrm{Cu}$-TP3939 is worthy of further investigation for the PET imaging of human 
Table II. Some analogs of VIP and their therapeutic effects.

\begin{tabular}{|c|c|c|c|}
\hline Analogs & Selectivity & $\begin{array}{c}\text { Affinity } \\
\left(\mathrm{IC}_{50}: \mathrm{nM}\right)\end{array}$ & Application \\
\hline VIPhyb & PAC antagonist & 300 & Inhibition of colon and breast cancer \\
\hline (SN)VIPhyb & VPAC1 antagonist & 30 & Inhibition of non-small lung cancer \\
\hline$\left[\mathrm{K}^{15}, \mathrm{R}^{16}, \mathrm{~L}^{27}\right]-\mathrm{VIP}(1-7) / \mathrm{GRF}(8-27)$ & VPAC1 antagonist & 10 & Inhibition various cancers \\
\hline VIP-LALA-E & VPAC1 agonist & 100 & Inhibition of breast cancer \\
\hline Ro 25-1553 & VPAC2 agonist & 1 & Therapeutic for bronchial athma \\
\hline BAY 55-9837 & VPAC2 agonist & 60 & Stimulation of insulin secretion \\
\hline stearyl-[Nle $\left.{ }^{17}\right]-$ VIP & Nonselective agonist & 5 & Inhibition of breast cancer \\
\hline$\left[\mathrm{R}^{15,20,21}, \mathrm{~L}^{17}\right]$-VIP-GRR & Nonselective agonist & 1.4 & Treatment of asthma and COPD \\
\hline$\left[\mathrm{R}^{15,20,21}, \mathrm{~L}^{17}\right]-\mathrm{VIP}(1-23)$ & Nonselective agonist & 48 & Relaxation of muscle \\
\hline
\end{tabular}

tumors and their metastases or recurrent lesions and for determining the efficacy of tumor therapy.

\section{Targeting VIP receptor for cancer molecular therapy}

VIP antagonist-based cancer therapy. Since VIP is thought to have growth promoting properties through VIP receptor activation $(71,72)$, the treatment of human tumors with a VIP antagonist may lead to the inhibition of tumor growth (Table II). The VIP-receptor antagonist VIPhyb was synthesized as a hybrid peptide of neurotensin and VIP consisting of an N-terminal Lys-Pro-Arg-Arg-Pro-Tyr (designed to increase membrane permeability), followed by the C-terminal 22 amino acids of VIP (73). This broad spectrum VIP receptor antagonist inhibited non-small cell lung cancer (73), breast cancer (74), and colon cancer (75) growth in vitro and in vivo. In addition, a further modification of VIPhyb was the addition of a stearyl group at the N-terminus and the exchange of the methionine at position 17 with norleucine. These modifications resulted in an antagonist with improved affinity (SN)VIPhyb (76). (SN)VIPhyb bound the VPAC1 receptor with an $\sim 10$-fold greater affinity than VIPhyb and acted as a cytostatic agent in non-small cell lung cancer (77) and pancreatic cancer (Table II) (78). Moreover, (SN)VIPhyb enhanced the anti-proliferative effects of chemotherapeutic agents on cancer cell lines (79).

To avoid the side effects of the broad-spectrum VIP receptor antagonists, new analogs selectively inhibiting each VIP receptor subtype may significantly prevent undesirable side effects, such as the inhibition of VPAC2 activation, which has been associated with glucose-dependent insulin secretion and bronchodilation (80). Recently, a VPAC1 antagonist conjugated to a high-molecular-weight PEG was synthesized, and the pharmacokinetic characteristics were improved without compromising functional activities. The results showed that the selective inhibition of the VPAC1 receptor is sufficient to prevent tumor proliferation, which suggests that a VPAC1selective antagonist may be a safe and effective tool for treating tumors (unpublished).

Cytotoxic peptide conjugate-based cancer therapy. Conventional chemotherapy is limited by multidrug resistance of tumor cells, toxicity to normal cells and a lack of tumor specificity. The more specific delivery of chemotherapeutic drugs to cancer cells can produce a higher drug concentration in tumors and reduce the toxicity to normal cells (81). Therefore, 'targeted therapy' was introduced with the aim of enhancing the specificity of chemotherapy and reducing the non-specific toxicity to normal cells (82). Since high-affinity VIP receptors are overexpressed on many tumors, they can be targeted using cytotoxic VIP conjugates.

A new cytotoxic analog of VIP-ellipticine was prepared that consisted of tetra- and pentapeptide ellipticine (E) attached to the C-terminus of VIP. The VIP-E conjugates functioned as VPAC1 receptor agonists, bound to VPACl receptors with high affinity and retained their anti-proliferative activity. The VIP-E conjugates were internalized by cancer cells expressing the VPAC1 receptor and were subsequently metabolized by proteolytic enzymes, leading to the release of ellipticine and cellular cytotoxicity. The VIP-E derivatives exhibited significant cytotoxicity toward breast cancer cells and lung cancer cells in vitro $(83,84)$. Subsequently, Moody et al $(85)$ extended these studies and synthesized VIP-camptothecin (CPT) conjugates that contain a novel carbamate linker with a built-in nucleophile associated releasing group, L2. The obtained conjugate (A-NL-K)-VIP-L2-CPT is metabolized by cytochrome P450 enzymes, releases CPT and exhibits cytotoxic effects on breast cancer cells.

Peptide-receptor radionuclide therapy (PRRT). As mentioned previously, VIP receptor-positive tumors can be targeted with radiolabeled VIP and its analogs $(52,61)$. It is theoretically possible to treat such tumors selectively with therapeutic nuclide-labeled VIP analogs. This peptide-receptor radionuclide therapy is based on the presence of high levels of VIP receptors in tumors and on their ability to form ligand-receptor complexes, which allows for the internalization and accumulation of the radiopharmaceuticals inside the tumors. Although there are many studies regarding somatostatin receptor-based radiotherapy $(51,86)$, there are currently no reports on VIP receptor radiotherapy for human tumors. One reason may be the lack of appropriate radiolabeled ligands. A second reason is certainly the inadequate tumor-to-non-tumor ratio for radiotherapy. In this case, VIP receptor-based PRRT could be 
highly radiotoxic to surrounding normal tissues, especially to radiosensitive tissues such as immune, lung, kidney and liver cells (51). Therefore, the development of new peptide analogs with increased binding affinity and specificity may lead to a higher accumulation of radioactivity in tumors and improve the efficacy of peptide receptor radionuclide therapy.

\section{Prospective and Conclusion}

VIP receptors are very important in the biology of many malignancies and are overexpressed in many tumors; thus, VIP receptors can be targeted by receptor-specific molecules. The generation of radiolabeled peptides has opened new avenues for the molecular imaging and therapy of tumors. Due to their low molecular weight, high-affinity, and good tissue/cell penetration, they are becoming ideal candidates for molecular imaging techniques and therapeutic interventions. To date, radiolabeled peptides specific for VIP receptors have evolved from the initial native VIP peptide into peptide analogs or peptide antagonists with improved pharmacokinetic profiles. Although a series of preclinical studies on VIP receptor-based imaging and therapy using radionuclide-labeled VIP and its analogs, antagonists and cytotoxic peptide conjugates have shown promising results, the therapeutic potential of VIP receptor-based radionuclide therapy must be refined and optimized.

Under the circumstances, it is necessary to develop novel peptide analogs with improved binding affinity, specificity and stability to result in a higher accumulation of radioactivity inside tumor cells. In a recent study, our research group identified a novel dodecapeptide that could specifically bind to the VPAC1 receptor with high affinity using a phage display peptide library. The results imply that the peptide may serve as a potential molecular imaging probe and therapeutic agent (87). Increasing the therapeutic window, which can be achieved by reducing the radiation toxicity to normal organs, could significantly enhance the therapeutic effects through increased injected radioactivity. Since the kidney has been one of the dose-limiting organs in some clinical studies, several standard procedures to reduce renal uptake have been developed and followed (88). Most importantly, the combination of radionuclide imaging and therapy with other diagnosis and treatment modalities, such as CT, MRI and chemotherapy, may greatly increase the efficiency of early diagnosis and treatment for the heterogeneous tumors.

Recently, the most common somatostatin receptor-based agent ${ }^{111}$ In-DTPA-pentetreotide (Octreoscan; Mallinckrodt) was approved by the US Food and Drug Administration for clinical somatostatin receptor imaging (89). Moreover, several ${ }^{90}$ Y-labeled octreotides were tested in different phase-I and phase-II clinical trials (90), and a major breakthrough in the tumor receptor-targeted imaging and therapy field may be on the way. The clinical success of somatostatin receptor imaging and therapy will provide insight into the exploration and development of VIP receptor-based imaging and therapy. Although there are still many other drawbacks to overcome in VIP receptor-based imaging and therapy, we believe that major progress will be made in preclinical settings. The importance of VIP receptors in tumor biology and the ability to predict responses to targeted therapy and monitor drug interventions suggest that VIP receptor imaging will be critical for onco- logic molecular imaging and will play a key role in cancer management in the future.

\section{References}

1. Ozben T: Mechanisms and strategies to overcome multiple drug resistance in cancer. FEBS Lett 580: 2903-2909, 2006.

2. Xie X, Tang B, Zhou J, Gao Q and Zhang P: Inhibition of the PI3K/Akt pathway increases the chemosensitivity of gastric cancer to vincristine. Oncol Rep 30: 773-782, 2013.

3. Pluchino KM, Hall MD, Goldsborough AS, Callaghan R and Gottesman MM: Collateral sensitivity as a strategy against cancer multidrug resistance. Drug Resist Updat 15: 98-105, 2012.

4. Burris HA III: Overcoming acquired resistance to anticancer therapy: focus on the PI3K/AKT/mTOR pathway. Cancer Chemother Pharmacol 71: 829-842, 2013.

5. Garanger E, Boturyn D and Dumy P: Tumor targeting with RGD peptide ligands-design of new molecular conjugates for imaging and therapy of cancers. Anticancer Agents Med Chem 7: 552-558, 2007.

6. Tolmachev V: Imaging of HER-2 overexpression in tumors for guiding therapy. Curr Pharm Des 14: 2999-3019, 2008.

7. Kaklamani V and O'Regan RM: New targeted therapies in breast cancer. Semin Oncol 31: 20-25, 2004.

8. Mankoff DA, Link JM, Linden HM, Sundararajan L and Krohn KA: Tumor receptor imaging. J Nucl Med 49: S149-S163, 2008.

9. Nunn AD: Molecular imaging and personalized medicine: an uncertain future. Cancer Biother Radiopharm 22: 722-739, 2007.

10. Mankoff DA: A definition of molecular imaging. J Nucl Med 48: N18-N21, 2007.

11. Sherwood NM, Krueckl SL and McRory JE: The origin and function of the pituitary adenylate cyclase-activating polypeptide (PACAP)/glucagon superfamily. Endocr Rev 21: 619-670, 2000.

12. Said SI and Mutt V: Polypeptide with broad biological activity: isolation from small intestine. Science 169: 1217-1218, 1970.

13. Piper PJ, Said SI and Vane JR: Effects on smooth muscle preparations of unidentified vasoactiv peptides from intestine and lung. Nature 225: 1144-1146, 1970.

14. Barbezat GO and Grossman MI: Intestinal secretion: stimulation by peptides. Science 174: 422-424, 1971 .

15. Gozes I,Fridkinb M, Hill JM and Brenneman DE: Pharmaceutical VIP: prospects and problems. Curr Med Chem 6: 1019-1034, 1999.

16. Gozes I and Furman S: VIP and drug design. Curr Pharm Des 9: 483-494, 2003

17. Tsukada T, Horovitch SJ, Montminy MR, Mandel G and Goodman RH: Structure of the human vasoactive intestinal polypeptide gene. DNA 4: 293-300, 1985.

18. Gozes I, Avidor R, Yahav Y, Katznelson D, Croce CM and Huebner K: The gene encoding vasoactive intestinal peptide is located on human chromosome 6p21-6qter. Hum Genet 75: 41-44, 1987

19. Davidson A, Moody TW and Gozes I: Regulation of VIP gene expression in general. Human lung cancer cells in particular. $\mathrm{J}$ Mol Neurosci 7: 99-110, 1996.

20. Itoh N, Obata K, Yanaihara N and Okamoto H: Human preprovasoactive intestinal polypeptide contains a novel PHI-27-like peptide, PHM-27. Nature 304: 547-549, 1983.

21. Bodner M, Fridkin M and Gozes I: Coding sequences for vasoactive intestinal peptide and PHM-27 peptide are located on two adjacent exons in the human genome. Proc Natl Acad Sci USA 82: 3548-3551, 1985

22. Vandermeers A, Vandenborre S, Hou X, de Neef P, Robberecht $P$, Vandermeers-Piret MC and Christophe J: Antagonistic properties are shifted back to agonistic properties by further N-terminal shortening of pituitary adenylate-cyclase-activating peptides in human neuroblastoma NB-OK-1 cell membranes. Eur J Biochem 208: 815-819, 1992.

23. Vaudry D, Gonzalez BJ, Basille M, Yon L, Fournier A and Vaudry H: Pituitary adenylate cyclase-activating polypeptide and its receptors: from structure to functions. Pharmacol Rev 52: 269-324, 2000.

24. Fahrenkrug J: VIP and PACAP. Results Probl Cell Differ 50: 221-234, 2010.

25. Dickson L and Finlayson K: VPAC and PAC receptors: From ligands to function. Pharmacol Ther 121: 294-316, 2009. 
26. Vaudry D, Falluel-Morel A, Bourgault S, Basille M, Burel D, Wurtz O, Fournier A, Chow BK, Hashimoto H, Galas L and Vaudry H: Pituitary adenylate cyclase-activating polypeptide and its receptors: 20 years after the discovery. Pharmacol Rev 61: 283-357, 2009.

27. Muller JM, Debaigt C, Goursaud S, Montoni A, Pineau N Meunier AC and Janet T: Unconventional binding sites and receptors for VIP and related peptides PACAP and PHI/PHM: an update. Peptides 28: 1655-1666, 2007.

28. Laburthe M, Couvineau A and Marie JC: VPAC receptors for VIP and PACAP. Recept Chann 8: 137-153, 2002.

29. Couvineau A, Lacapere JJ, Tan YV, Rouyer-Fessard C, Nicole P and Laburthe M: Identification of cytoplasmic domains of hVPAC1 receptor required for activation of adenylyl cyclase. Crucial role of two charged amino acids strictly conserved in class II G protein-coupled receptors. J Biol Chem 278: 24759-24766, 2003

30. Dickson L, Aramori I, McCulloch J, Sharkey J and Finlayson K: A systematic comparison of intracellular cyclic AMP and calcium signalling highlights complexities in human VPAC/PAC receptor pharmacology. Neuropharmacology 51: 1086-1098, 2006.

31. Barrie AP, Clohessy AM, Buensuceso CS, Rogers MV and Allen JM: Pituitary adenylyl cyclase-activating peptide stimulates extracellular signal-regulated kinase 1 or 2 (ERK1/2) activity in a Ras-independent, mitogen-activated protein Kinase/ ERK kinase 1 or 2 -dependent manner in PC12 cells. J Biol Chem 272: 19666-19671, 1997.

32. Lelièvre V, Pineau $\mathrm{N}$, Du J, Wen $\mathrm{CH}$, Nguyen $\mathrm{T}$, Janet $\mathrm{T}$, Muller JM and Waschek JA: Differential effects of peptide histidine isoleucine (PHI) and related peptides on stimulation and suppression of neuroblastoma cell proliferation. A novel VIP-independent action of PHI via MAP kinase. J Biol Chem 273: 19685-19690, 1998.

33. Delgado $M$ and Ganea D: Vasoactive intestinal peptide and pituitary adenylate cyclase-activating polypeptide inhibit interleukin-12 transcription by regulating nuclear factor kappaB and Ets activation. J Biol Chem 274: 31930-31940, 1999.

34. Hashimoto H, Shintani N, Tanaka K, Mori W, Hirose M, Matsuda T, Sakaue M, Miyazaki J, Niwa H, Tashiro F, Yamamoto K, Koga K, Tomimoto S, Kunugi A, Suetake S and Baba A: Altered psychomotor behaviors in mice lacking pituitary adenylate cyclase-activating polypeptide (PACAP). Proc Natl Acad Sci USA 98: 13355-13360, 2001.

35. Jozsa R, Hollosy T, Nemeth J, Tamás A, Lubics A, Jakab B, Olah A, Arimura A and Reglödi D: Presence of PACAP and VIP in embryonic chicken brain. Ann NY Acad Sci 1070: 348-353, 2006.

36. Valdehita A, Carmena MJ, Collado B, Prieto JC and Bajo AM: Vasoactive intestinal peptide (VIP) increases vascular endothelial growth factor (VEGF) expression and secretion in human breast cancer cells. Regul Pept 144: 101-108, 2007.

37. Valdehita A, Bajo AM, Schally AV, Varga JL, Carmena MJ and Prieto JC: Vasoactive intestinal peptide (VIP) induces transactivation of EGFR and HER 2 in human breast cancer cells. Mol Cell Endocrinol 302: 41-48, 2009.

38. Sreedharan SP, Patel DR, Huang JX and Goetzl EJ: Cloning and functional expression of a human neuroendocrine vasoactive intestinal peptide receptor. Biochem Biophys Res Commun 193 546-553, 1993

39. Usdin TB, Bonner TI and Mezey E: Two receptors for vasoactive intestinal polypeptide with similar specificity and complementary distributions. Endocrinology 135: 2662-2680, 1994.

40. Wei Y and Mojsov S: Tissue specific expression of different human receptor types for pituitary adenylate cyclase activating polypeptide and vasoactive intestinal polypeptide: implications for their role in human physiology. J Neuroendocrinol 8: 811-817, 1996.

41. Moller K and Sundler F: Expression of pituitary adenylate cyclase activating peptide (PACAP) and PACAP type I receptors in the rat adrenal medulla. Regul Pept 63:129-139, 1996.

42. Zeng N, Kang T, Lyu RM, Wong H, Wen Y, Walsh JH, Sachs G and Pisegna JR: The pituitary adenylate cyclase activating polypeptide type 1 receptor (PAC1-R) is expressed on gastric ECL cells: evidence by immunocytochemistry and RT-PCR. Ann NY Acad Sci 865: 147-156, 1998.

43. Reubi JC, Läderach U, Waser B, Gebbers JO, Robberecht P and Laissue JA: Vasoactive intestinal peptide/pituitary adenylate cyclase-activating peptide receptor subtypes in human tumors and their tissues of origin. Cancer Res 60: 3105-3112, 2000.
44. Reubi JC, Körner M, Waser B, Mazzucchelli L and Guillou L: High expression of peptide receptors as a novel target in gastrointestinal stromal tumours. Eur J Nucl Med Mol Imaging 31: 803-810, 2004.

45. Gozes I and Furman S: Clinical endocrinology and metabolism. Potential clinical applications of vasoactive intestinal peptide: a selected update. Best Pract Res Clin Endocrinol Metab 18: 623-640, 2004

46. Whitmarsh AJ and Davis RJ: Transcription factor AP-1 regulation by mitogen-activated protein kinase signal transduction pathways. J Mol Med 74: 589-607, 1996.

47. Casibang M, Purdom S, Jakowlew S, Neckers L, Zia F, Ben-Av P, Hla T, You L, Jablons DM and Moody TW: Prostaglandin E and vasoactive intestinal peptide increase vascular endothelial cell growth factor mRNAs in lung cancer cells. Lung Cancer 31: 203-212, 2001

48. Mankoff DA, O'Sullivan F, Barlow WE and Krohn KA Molecular imaging research in the outcomes era: measuring outcomes for individualized cancer therapy. Acad Radiol 14: 398-405, 2007.

49. Goldenberg DM, DeLand F, Kim E, Bennett S, Primus FJ, van Nagell JR Jr, Estes N, DeSimone P and Rayburn P: Use of radiolabeled antibodies to carcinoembryonic antigen for the detection and localization of diverse cancers by external photoscanning. N Engl J Med 298: 1384-1386, 1978.

50. Behr TM, Memtsoudis S, Sharkey RM, Blumenthal RD, Dunn RM, Gratz S, Wieland E, Nebendahl K, Schmidberger H, Goldenberg DM and Becker W: Experimental studies on the role of antibody fragments in cancer radio-immunotherapy: influence of radiation dose and dose rate on toxicity and anti-tumor efficacy. Int J Cancer 77: 787-795, 1998.

51. Reubi JC: Peptide receptors as molecular targets for cancer diagnosis and therapy. Endocr Rev 24: 389-427, 2003.

52. Virgolini I, Raderer M, Kurtaran A, Angelberger P, Banyai S, Yang Q, Li S, Banyai M, Pidlich J, Niederle B, Scheithauer W and Valent P: Vasoactive intestinal peptide-receptor imaging for the localization of intestinal adenocarcinomas and endocrine tumors. N Engl J Med 33: 1116-1121, 1994.

53. Raderer M, Kurtaran A, Hejna M, Vorbeck F, Angelberger P, Scheithauer W and Virgolini I: ${ }^{123 I}$-labelled vasoactive intestinal peptide receptor scintigraphy in patients with colorectal cancer. Br J Cancer 78: 1-5, 1998.

54. Raderer M, Kurtaran A, Yang Q, Meghdadi S, Vorbeck F, Hejna M, Angelberger P, Kornek G, Pidlich J, Scheithauer W and Virgolini I: Iodine-123-vasoactive intestinal peptide receptor scanning in patients with pancreatic cancer. J Nucl Med 39: 1570-1575, 1998.

55. Virgolini I, Kurtaran A, Leimer M, Kaserer K, PeckRadosavljevic M, Angelberger P, Hübsch P, Dvorak M, Valent P and Niederle B: Location of a VIPoma by iodine-123-vasoactive intestinal peptide scintigraphy. J Nucl Med 39: 1575-1579, 1998.

56. Virgolini I, Kurtaran A, Raderer M, Leimer M, Angelberger P, Havlik E, Li S, Scheithauer W, Niederle B and Valent P: Vasoactive intestinal peptide receptor scintigraphy. J Nucl Med 36: 1732-1739, 1995

57. Raderer M, Becherer A, Kurtaran A, Angelberger P, Li S, Leimer M, Weinlaender G, Kornek G, Kletter K, Scheithauer W and Virgolini I: Comparison of iodine-123-vasoactive intestinal peptide receptor scintigraphy and indium-111-CYT-103 immunoscintigraphy. J Nucl Med 37: 1480-1487, 1996.

58. Thakur ML, Marcus CS, Saeed S, Pallela V, Minami C, Diggles L, Le Pham H, Ahdoot R and Kalinowski EA: ${ }^{99 \mathrm{~m} T c-}$ labeled vasoactive intestinal peptide analog for rapid localization of tumors in humans. J Nucl Med 41: 107-110, 2000.

59. Pallela VR, Thakur ML, Chakder $S$ and Rattan S: ${ }^{99 \mathrm{~m}}$ Tc-labeled vasoactive intestinal peptide receptor agonist: functional studies. J Nucl Med 40: 352-360, 1999.

60. Thakur ML, Marcus CS, Saeed S, Pallela V, Minami C, Diggles L, Pham HL, Ahdoot R, Kalinowski EA and Moody T: Imaging tumors in humans with Tc-99m-VIP. Ann NY Acad Sci 921: 37-44, 2000.

61. Rao PS, Thakur ML, Pallela V, Patti R, Reddy K, Li H, Sharma S, Pham HL, Diggles L, Minami C and Marcus CS: ${ }^{99 \mathrm{~m}} \mathrm{Tc}$ labeled VIP analog: evaluation for imaging colorectal cancer. Nucl Med Biol 28: 445-450, 2001.

62. Kothari K, Prasad S, Korde A, Mukherjee A, Mathur A, Jaggi M, Venkatesh M, Pillai AM, Mukherjee R and Ramamoorthy N: ${ }^{99 \mathrm{~m}} \mathrm{Tc}(\mathrm{CO}) 3-\mathrm{VIP}$ analogues: preparation and evaluation as tumor imaging agent. Appl Radiat Isot 65: 382-386, 2007. 
63. Moody TW, Leyton J, Unsworth E, John C, Lang L and Eckelman WC: $\left(\mathrm{Arg}^{15}, \mathrm{Arg}^{21}\right)$ VIP: evaluation of biological activity and localization to breast cancer tumors. Peptides 19: 585-592, 1998

64. Jagoda EM, Aloj L, Seidel J, Lang L, Moody TW, Green S, Caraco C, Daube-Witherspoon M, Green MV and Eckelman WC: Comparison of an ${ }^{18} \mathrm{~F}$ labeled derivative of vasoactive intestinal peptide and 2-deoxy-2-[ $\left.{ }^{18} \mathrm{~F}\right]$ fluoro-D-glucose in nude mice bearing breast cancer xenografts. Mol Imaging Biol 4: 369-379, 2002 .

65. Cheng D, Yin D, Zhang L, Wang M, Li G and Wang Y: Radiosynthesis of ${ }^{18} \mathrm{~F}-\left(\mathrm{R}^{8,15,21}, \mathrm{~L}^{17}\right)$-vasoactive intestinal peptide and preliminary evaluation in mice bearing C26 colorectal tumours. Nucl Med Commun 28: 501-506, 2007.

66. Cheng D, Yin D, Li G, Wang M, Li S, Zheng M, Cai H and Wang Y: Radiolabeling and in vitro and in vivo characterization of $\left[{ }^{18} \mathrm{~F}\right] \mathrm{FB}-\left[\mathrm{R}^{8,15,21}, \mathrm{~L}^{17}\right]$-VIP as a PET imaging agent for tumor overexpressed VIP receptors. Chem Biol Drug Des 68: 319-325, 2006

67. Chen X, Edwards WB, Anderson CJ, Mccarthy TJ and Welch MJ: Solid phase synthesis of TETA conjugated vasoactive intestinal peptide and in vivo behavior of copper-64 radiolabeled VIP conjugate. J Labelled Compds Radiopharm 44: S688-S690, 2001.

68. Thakur ML, Aruva MR, Gariepy J, Acton P, Rattan S, Prasad S Wickstrom E and Alavi A: PET imaging of oncogene overexpression using ${ }^{64} \mathrm{Cu}$-vasoactive intestinal peptide (VIP) analog: comparison with ${ }^{99 m}$ Tc-VIP analog. J Nucl Med 45: 1381-1389, 2004.

69. Zhang K, Aruva MR, Shanthly N, Cardi CA, Rattan S, Patel C, Kim C, McCue PA, Wickstrom E and Thakur ML: PET imaging of VPAC1 expression in experimental and spontaneous prostate cancer. J Nucl Med 49: 112-121, 2008.

70. Zhang K, Aruva MR, Shanthly N, Cardi CA, Patel CA, Rattan S, Cesarone G, Wickstrom E and Thakur ML: Vasoactive intestinal peptide (VIP) and pituitary adenylate cyclase activating peptide (PACAP) receptor specific peptide analogues for PET imaging of breast cancer: In vitro/in vivo evaluation. Regul Pept 144: 91-100, 2007.

71. Collado B, Carmena MJ, Clemente C, Prieto JC and Bajo AM: Vasoactive intestinal peptide enhances growth and angiogenesis of human experimental prostate cancer in a xenograft model. Peptides 28: 1896-1901, 2007.

72. Fernández-Martínez AB, Bajo AM, Sánchez-Chapado M, Prieto JC and Carmena MJ: Vasoactive intestinal peptide behaves as a pro-metastatic factor in human prostate cancer cells. Prostate 69: 774-786, 2009.

73. Moody TW, Zia F, Draoui M, Brenneman DE, Fridkin M, Davidson A and Gozes I: A vasoactive intestinal peptide antagonist inhibits non-small cell lung cancer growth. Proc Natl Acad Sci USA 90: 4345-4349, 1993.

74. Zia H, Hida T, Jakowlew S, Birrer M, Gozes Y, Reubi JC, Fridkin M, Gozes I and Moody TW: Breast cancer growth is inhibited by vasoactive intestinal peptide (VIP) hybrid, a synthetic VIP receptor antagonist. Cancer Res 56: 3486-3489, 1996.
75. Levy A, Gal R, Granoth R, Dreznik Z, Fridkin M and Gozes I: In vitro and in vivo treatment of colon cancer by VIP antagonists. Regul Pept 109: 127-133, 2002.

76. Moody TW, Jensen RT, Fridkin M and Gozes I: (N-stearyl, norleucine 17) VIP hybrid is a broad spectrum vasoactive intestinal peptide receptor antagonist. J Mol Neurosci 18: 29-35, 2002.

77. Moody TW, Leyton J, Coelho T, Jakowlew S, Takahashi K, Jameison F, Koh M, Fridkin M, Gozes I and Knight M: (Stearyl, Norleucine 17) VIP hybrid antagonizes VIP receptors on non-small cell lung cancer cells. Life Sci 61: 1657-1666, 1997.

78. Zia H, Leyton J, Casibang M, Hau V, Brenneman D, Fridkin M, Gozes I and Moody TW: (N-stearyl, norleucine17) VIP hybrid inhibits the growth of pancreatic cancer cell lines. Life Sci 66: 379-387, 2000.

79. Moody TW, Leyton J, Chan D, Brenneman DC, Fridkin M, Gelber E, Levy A and Gozes I: VIP receptor antagonists and chemotherapeutic drugs inhibit the growth of breast cancer cells. Breast Cancer Res Treat 68: 55-64, 2001.

80. Pan CQ, Hamren S, Roczniak S, Tom I and DeRome M: Generation of PEGylated VPAC1-selective antagonists that inhibit proliferation of a lung cancer cell line. Peptides 29: 479-486, 2008.

81. Schally AV and Nagy A: Chemotherapy targeted to cancers through tumoral hormone receptors. Trends Endocrinol Metab 15: 300-310, 2004.

82. Kim JA: Targeted therapies for the treatment of cancer. Am J Surg 186: 264-268, 2003.

83. Moody TW, Czerwinski G, Tarasova NI and Michejda CJ: VIP-ellipticine derivatives inhibit the growth of breast cancer cells. Life Sci 71: 1005-1014, 2002.

84. Moody TW, Czerwinski G, Tarasova NI, Moody DL and Michejda CJ: The development of VIP-ellipticine conjugates. Regul Pept 123: 187-192, 2004

85. Moody TW, Mantey SA, Fuselier JA, Coy DH and Jensen RT: Vasoactive intestinal peptide-camptothecin conjugates inhibit the proliferation of breast cancer cells. Peptides 28: 1883-1890, 2007.

86. Zaccaro L, Del Gatto A, Pedone C and Saviano M: Peptides for tumour therapy and diagnosis: current status and future directions. Curr Med Chem 16: 780-795, 2009.

87. Tang B, Li Z, Huang D, Zheng L and Li Q: Screening of a specific peptide binding to VPAC1 receptor from a phage display peptide library. PLoS One 8: e54264, 2013.

88. de Visser M, Verwijnen SM and de Jong M: Update: improvement strategies for peptide receptor scintigraphy and radionuclide therapy. Cancer Biother Radiopharm 23: 137-157, 2008.

89. Balon HR, Goldsmith SJ, Siegel BA, Silberstein EB, Krenning EP, Lang $\mathrm{O}$ and Donohoe KJ: Procedure guideline for somatostatin receptor scintigraphy with (111)In-pentetreotide. J Nucl Med 42: 1134-1138, 2001.

90. Kwekkeboom DJ, Kam BL, van Essen M, Teunissen JJ, van Eijck CH, Valkema R, de Jong M, de Herder WW and Krenning EP: Somatostatin-receptor-based imaging and therapy of gastroenteropancreatic neuroendocrine tumors. Endocr Relat Cancer 17: R53-R73, 2010. 